\title{
Meaningful statistics in professional practices as a bridge between mathematics and science: an evaluation of a design research project
}

\author{
Adri Dierdorp*, Arthur Bakker, Jan A van Maanen and Harrie MC Eijkelhof
}

\begin{abstract}
Background: Creating coherence between school subjects mathematics and science and making these school subjects meaningful are still topical challenges. This study investigates how students make meaningful connections between mathematics, statistics, science and applications when they engage in a specially developed unit that is based on professional practices in which mathematical, statistical and scientific knowledge are used. The central question is to what extent professional practices can serve as meaningful contexts for senior high school students (aged 16 to 17) to help them make connections between mathematics, statistics, science and professional practices. In order to answer this question, we focused on two sub-questions: (1) How meaningful do students find an instructional unit that is based on professional practices in which statistics plays a role? and (2) To what extent are students able to show awareness of the connections between mathematics, statistics, science within the instructional unit and professional practices?
\end{abstract}

Results: Questionnaires on the opinions of 415 students (388 before and 27 after completing two chapters of the unit) on the educational strategy and student work are used to answer the central question. The analysis of responses to questionnaires shows that students consider an educational strategy based on authentic professional practices meaningful. These results are also confirmed by the findings in the analysis of the second sub-question.

Conclusions: The results indicate that an educational strategy based on professional practices can help students make connections between mathematics, statistics, science and professional practices.

Keywords: Coherence; statistical reasoning; inferential reasoning; authentic professional practice; upper secondary education; meaningful education

\section{Background}

The purpose of this study is to determine whether senior high school students learn to see the connections between mathematics, statistics, science and some professional practices through an instructional unit based on professional practices in which statistics is used. Statistics is seen here as a possible bridge between mathematics and some of the natural sciences, because many scientists frequently apply statistical and mathematical techniques (Erickson 2002). Statistics is a mathematical science, but not part of mathematics (Moore and Cobb 2000), although in most countries statistics is part of the secondary education

\footnotetext{
* Correspondence: a.dierdorp@uu.nl

Faculty of Science, Department of Mathematics, The Freudenthal Institute for Science and Mathematics Education, Utrecht University, Princetonplein 5,
} Utrecht 3508 AD, The Netherlands mathematics curriculum (Gattuso 2006). Statistics could therefore function as a bridge connecting a part of mathematics with the sciences. Ben-Zvi and Garfield (2008), p. 355 wrote We conclude with an argument that statistics should be viewed as a bridge between mathematics and science and should be taught in both disciplines. One of their arguments was (p. 359) that it provides the mathematical foundations for analyzing data gathered in the real world (science). But would students also recognize this, and would it improve their learning?

It is important that students experience coherence between different disciplines. Mathematics and statistics provide the tools by which quantitative relationships in the natural sciences can be modelled, calculated, represented, and predicted, and the natural sciences provide 
relevant contexts in which mathematical and statistical knowledge can be applied (Davison et al. 1995). Therefore, international and Dutch national committees (AAAS 1989; cTWO 2007; Boersma et al. 2007; NCTM 2000; $\mathrm{NiNa}$, Commissie Vernieuwing Natuurkundeonderwijs havo/vwo 2010; Apotheker et al. 2010; NRC, National Research Council 1996; Stuurgroep-NLT 2007) advocate the integration of mathematics and the natural sciences (science, in short) where possible.

However, making the relationship between science and contexts clear to students appears to be difficult (Berlin and White 2012). Often, students in secondary education do not experience the meaningfulness of science because they experience learning within school subjects as a train with individual waggons, whose windows are blinded and only the driver on the engine knows where the journey goes to (Claxton 1991). A report on alignment between mathematics and physics (Gellish et al. 2007) speaks in this context of sectarianism. This compartmented thinking also makes it difficult for students to recognize what they have learned as meaningful, and apply it to another subject or in other contexts (Bransford et al. 2000). More curricular coherence is needed. Berlin and Lee (2005) provide an overview of the US efforts to curricular cohesion in the period 1970 to 2001. In this period, the number of publications on curricular coherence increased significantly, but the authors conclude that more insight into how more cohesion can be achieved is needed.

The literature provides no univocal definition of curricular coherence (Hurley 2001), which is not surprising given the various manifestations of a curriculum - intended, implemented and attained curriculum (Van den Akker 2009). The intended curriculum includes the vision that not only lies at the basis of the curriculum but also the formal texts in which the curriculum is described. Within an intended curriculum, coherence refers to aligning the curriculum between or within different school curricula. Intended cohesion must be reflected in the implemented curriculum that includes the interpretations of teachers and the resulting practice of education. An attained curriculum refers to the learning outcomes achieved and the experiences of the students. As several researchers (e.g., Newmann et al. 2001; Rudduck and Wallace 1994) point out, there is very little research on coherence in the attained curriculum, in other words: how curricular coherence works for students (Frykholm and Glasson 2005) and how students make and observe connections.

Furner and Kumar (2007) underline the recommendations of Berlin and White (1992) and Sunal and Furner (1995) for the integration of mathematics and science by promoting overlapping subject matter and supporting students to search for patterns in data to get a more meaningful view of scientific phenomena. Sunal and Furner also stress the importance of bridging the gap between school practice and extracurricular life. Bennett et al. (2007) provide clear evidence that context-based education contributes to the making of meaningful education. The affective reactions and motivation of their students gave them indications that this strategy leads to better understanding of science education, a finding that is supported by Scott et al. (2011). They investigated how teachers and students make connections in meaningful interactions between teaching and learning of scientific concepts, but their study did not pay special attention to mathematics.

Considering these challenges to achieve coherence and meaningful science education, innovation commissions for science and mathematics education in the Netherlands advise using the so-called concept-context approach: students are expected to learn concepts in meaningful contexts. These contexts may be based on authentic practices, such as scientific or professional practices in which scientific knowledge is applied. The use of these practices is a possible way to make science education meaningful because when students experience a balance between such professional practice and school practice, they can become more receptive to the concepts (Anderson and Sungur 1999).

Meaningful scientific concepts and contexts involve various aspects. To define meaningfulness, we consider, according to the literature, the following aspects:

- Usefulness

- Motivation

- Application

- Authenticity

- Connections.

It is important that students experience the usefulness of education by seeing the purpose (need to know) of what they need to learn (Westbroek 2005) and become motivated by the context to engage in the instructional unit (Prins 2010). Engagement in the sense of motivated behaviour, according to the learning motivation model of Eccles et al. (1993), is determined by the value that students assign to their task (cf. Volman 2011). Furthermore, students recognize their education as more meaningful if they are able to apply the concepts learned (Boersma et al. 2007) and if it is authentic (Volman 2011). Clarke (1988) argued that students experience lessons as more meaningful when dealing with authentic contexts such as sporting contexts. Although for biology and chemistry several mono-disciplinary units based on authentic professional practices exist (Prins 2010; Westra 2008), there is little research on how the relationship between school subjects can be promoted by materials that are 
based on professional practices where knowledge from different sciences is integrated.

In the current study, we focus on coherence between mathematics, statistics, science and professional practices for the attained curriculum as the ability of students to make sense of the contexts so that they can apply scientific and mathematical knowledge when solving authentic problems. This fits the definition of the intended curriculum in which mathematics and science are seen as an interdisciplinary mix in which connections between these disciplines are placed while the subject specific concepts remain recognizable (Lederman and Niess 1997).

In this article, we test our assumption that education is meaningful for students and that students can apply their learning in other disciplines or in other contexts when it is based on problems in authentic professional practices. We assume a reciprocal relation between coherence and meaning. When students observe coherence between different subjects, these subjects will have more meaning for them, and vice versa: meaning helps them to see coherence. We first give an overview of the efforts in the Netherlands to facilitate coherence between the subjects and then discuss the rationale for the choice of an instructional unit based on professional practices.

\section{Coherent teaching in the Netherlands}

One of the objectives of the Dutch government during the past decade was to promote greater coherence between school subjects, but curricular coherence is still fragile and needs continued attention (Boersma et al. 2010; Nieveen et al. 2011). The introduction of a new curriculum for upper secondary school (1998) intended, among many other aims, to establish such coherence. In 1999, the Sonate project (coherent education in science and technology) started to monitor good practice in the field of coherent teaching in lower secondary and in the science stream of upper secondary (Geraedts et al. 2001). At the end of this project in 2004, the team concluded that intrinsic coherence in educational practice was still a blank spot. The Sonate project was continued in the Salvo project (coherent learning in secondary education), which among other things sought to develop exemplary material for an on-going learning strand about the relationships between quantities - a theme that lends itself to a coherent approach (Mooldijk and Sonneveld 2010). A recent initiative to foster interdisciplinary cohesion is the introduction of Nature, Life and Technology (NLT), a new three year course in addition to physics, chemistry, biology and mathematics (NLT Steering Committee 2007).

Some innovation commissions for science and mathematics education have published documents in which they tried to make visible the link between the new syllabuses (Boersma et al. 2010). In these documents, there is little attention to the possible role of statistics in creating coherence, although statistics seems appropriate to let students experience such coherence. Commissie Toekomst Wiskunde Onderwijs (cTWO), the commission for mathematics, only states (2007) that it is important for students to learn that mathematics is indispensable in engineering and science and that it is closely intertwined with everyday life. Here, statistics is mentioned as one of the integrating factors. Furthermore, in the commission reports of mathematics and physics, cTWO and NiNa (Gellish et al. 2007; $\mathrm{NiNa}$, Commissie Vernieuwing Natuurkundeonderwijs havo/vwo 2010), not much is written about statistics. Rather, modelling is the preferred tool for students to experience the coherence between the various disciplines.

\section{Professional practices as a basis for an instructional unit}

Authentic practices are en vogue as an inspiration for teaching and learning strategies. Educational research about science and mathematics shows how one can develop teaching materials based on authentic scientific or professional practices (e.g., Lee and Songer 2003; Westbroek 2005). Lee and Songer (2003) used the practice of weather forecasting, and Westbroek (2005) used the practice of testing water quality to involve students in learning chemistry. In this way, Westbroek made the featured chemical concepts more meaningful for students. A disadvantage of this teaching strategy is that there will be so much emphasis on the professional aspects that little school knowledge is learned. Conversely, mathematics education contexts, if they even exist, are usually subordinated to the concepts to be learned (Boaler 1993).

For a good balance, the steering committee New Chemistry advises to use the concept-context (often referred to as context based) approach. The committee states that major developments in scientific research as well as in industry (e.g., nanotechnology) are important since they can offer students a meaningful curriculum based on interdisciplinary contexts (Apotheker et al. 2010). The Commission Renewal Biology Education (CVBO) opted explicitly for social practices, such as scientific or professional practices, as an inspiration for teaching learning strategies (Boersma et al. 2007), in its concept-context approach. This approach is founded on the cultural-historical activity theory (Van Oers 1987). In relation to coherence, we suggest that the concept-context approach overcomes the problem that coherence is not enough for students to promote their ability to make connections. For example, Mooldijk and Sonneveld (2010) examined students in a strongly coherent programme of mathematics and physics. They found that students still had problems to use their gained knowledge to deal with connections between variables. Students tended to look for correlations between variables, but they did not consider the reliability of the data. We suggest that 
applying the concept-context approach encourages students to consider the reliability of the data because results are meaningless for a context if there is no reliability check and if no connection is made to the context.

We feel supported by Geraedts et al. (2006), p. 311 who wrote:

recontextualizing a concept, skill, or competency to other disciplinary or daily-life contexts requires an understanding of the nature of the (disciplinary) context in which it is acquired.

In order to establish coherence or maintain meaningfulness of concepts to students, the concept-context approach could be used to balance between scientific practices and school practices. Related to this, Whitelegg and Parry (1999) wrote:

Many different approaches, from applications of physics principles introduced in a traditional way after the concepts have been taught, to a more ambitious programme where real-life scenarios, which structure the content of the programme, are investigated and understood in terms of their physics content.

In this study, we used professional practices as real-life scenarios to inspire our educational materials. For educational purposes, professional practices are first educationalized, because the authentic practices are often too complicated for students. Also, professional practice and educational practice have different purposes. In a professional practice, one may want to test or optimize a process, while in a teaching practice, students have to learn something.

We have, just as Westra (2008), chosen to offer students the concepts within different educationalized practices, so that they learn to apply the concepts in several different contexts. The underlying idea is to reveal to students the relationship between mathematics, statistics, and science within the contexts in which these disciplines function. In the present study, correlation and regression are chosen as statistical concepts because they are applicable in science and the students are at a level to master them. Moreover, these concepts receive little attention in upper secondary level curricula. During the especially designed instructional unit, students themselves reach the idea that they need statistical techniques such as correlation and regression models to solve the real problems that they are facing in the authentic professional practices (Dierdorp et al. 2011). They need both mathematical and scientific concepts. The instructional unit is called statistics as a bridge between mathematics and the natural sciences (see Additional file 1). In the unit, there is a focus on the understanding of the new concepts, which at the same time highlight the connections between mathematics, statistics and the respective professional practices.

\section{Connections between mathematics, statistics, science and professional practice}

In accordance with the concept-context approach, we have chosen not only to investigate disciplinary coherence but also coherence between disciplines and their areas of application (contexts). Disciplinary coherence is visible in some disciplines such as mechanics, a section of physics with a strong mathematical foundation. Modelling is often an interdisciplinary activity, which is also recommended to students to clarify the coherence between science subjects (Van de Giessen et al. 2007). As a premise that underlies our investigation, we suspect that an educational strategy in which statistics functions in a professional practice will work as a bridge between mathematics and some science (Figure 1); we see it as a promising approach that has received little attention in the literature. Although there are direct connections between mathematics and the natural sciences (e.g., through differential equations), we focus here on a more indirect relationship, generated by the application of statistics within professional practices. In this section, we discuss the relationships that are central to this article.

\section{Mathematics and statistics (MS)}

Mathematicians generally strive to abstract the mathematics from the contexts, so that underlying structures become clear, while statisticians need to precisely analyse the data (Rossman et al. 2006). Mathematics looks for statements or theoretical underpinnings of a phenomenon and seeks, through statistical analysis, for significance (Moore and Cobb 2000). Statistics, for example, in the form of correlation and regression, can be used to derive a mathematical model. Mathematical procedures such as calculation methods or solving equations should in turn involve statistics to substantiate or justify.

\section{Statistics and natural science (SN)}

As mentioned, correlation and regression are often used for the analysis of data collected in a scientific experiment, with the purpose of eventually finding a model. In such situations, statistics provides a bridge between mathematics and natural science. One example in our study is the determination of the moment in the training of an athlete when the metabolism turns from the aerobic to the anaerobic phase. Data on the athletes pulse rate are collected while the training effort increases, and subsequently statistical techniques such as correlation and regression are used to create a mathematical model 


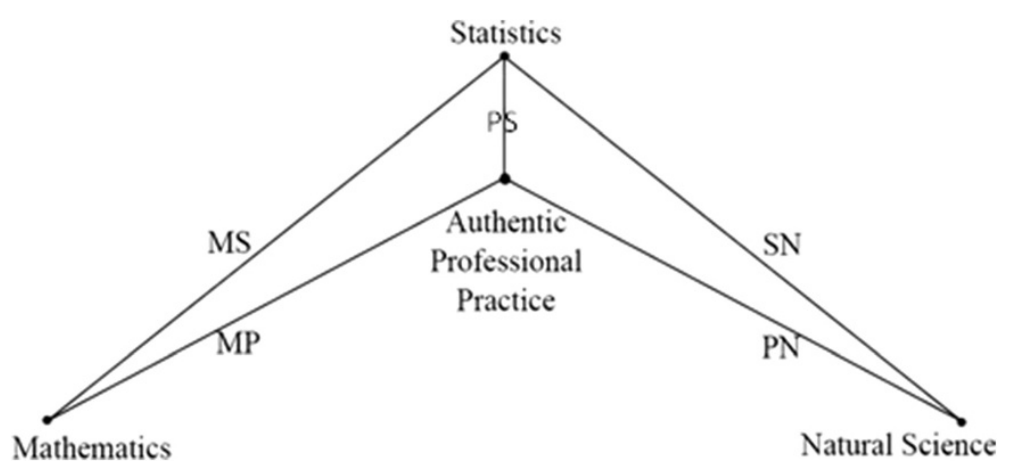

Figure 1 Bridge metaphor. Statistics used in a professional practice as a bridge between mathematics and natural science.

with the purpose of giving optimal training advice (Gellish et al. 2007).

\section{Professional practice and statistics (PS)}

Statistics is used in many professional practices. One example in our study is the analysis of dike heights. All dikes sag continuously. In order to predict when a dike should be raised, data about the height of a dike are regularly collected with helicopters and satellites. Regression is then used to create a mathematical model which helps to minimize the risk of flooding. Another example is the Dutch Metrology Institute, the former institute of weights and measures, which works with regression models for calibrating measuring instruments. Comparison of the characteristics (correlation coefficient and regression line) of a measuring instrument of unknown quality with the characteristics of a calibrated instrument provides the institute with a proof of the quality level of the instrument being tested.

\section{Mathematics and professional practice (MP)}

In the previous examples of professional practices, there was a clear link with mathematics. Galbraith and Stillmann (2006), p. 150 write In some cases, an adequate response requires arguments that integrate mathematical knowledge with the impact of this knowledge in the real situations to justify interpretation. It is important that students understand how a model works and how mathematical concepts, such as solving equations, play a role in creating or interpreting the models.

\section{Professional practice and natural science (PN)}

If a professional scientist has collected experimental data and has found a mathematical model that represents these data, it must be interpreted in order to draw conclusions. In the example of dike subsidence, it is important to understand that landslides or erosion can be responsible for this subsidence. Also, a natural phenomenon such as heavy rain provides much variability around a model.
These aspects will have to be estimated and discussed as part of a professional advice. It is important that students understand that nature does not exactly behave as the model does, and that there is always variability (Wild and Pfannkuch 1999).

We note that the boundaries between the five links are not always sharp. Mathematical statistics, for example, will be located somewhere between mathematics and statistics, and scientific researchers are at the same time professional practitioners.

\section{Research questions}

To investigate whether a teaching strategy based on professional practices enables students to make meaningful connections between mathematics, statistics, science and professional practice, we have designed an instructional unit, based on three professional practices: that of a sports physiologist, of an official of Public Works and Water Management, and of an analyst at the Dutch Metrology Institute. In these three environments, the professionals work with statistical techniques to analyse their data. To investigate as to what extent the unit contributes to achieving our goals, we address the following main question:

To what extent can professional practices serve as meaningful contexts to show students connections between mathematics, statistics, science and professional practices?

More specifically, we answer the following two research questions:

RQ1: How meaningful do students find an instructional unit that is based on professional practices in which statistics plays a role? RQ2: To what extent are students able to show awareness of the connections between mathematics, statistics, science within the instructional unit, and professional practices? 


\section{Methods}

\section{Educational unit}

The study presented here is part of a larger project, which works along the lines of design-based research (Barab and Squire 2004; Van den Akker et al. 2006). It consists of six design cycles with professional practices as a basis for teaching learning strategies. For the selection of the three professional practices, we started with a preliminary study, which included a literature review and interviews with experts, practitioners, teachers and students. Criteria for the selection of practices were (cf. Prins et al. 2008) as follows:

- The practitioner uses correlation and regression in data modelling.

- The actions of at least one professional practice are educationalized into teaching activities, in which students can perform a short, relevant experiment of their own.

- For students, the professional practice is easy to recognize.

- Students can see the relevance of the knowledge that the practitioner uses.

Based on each of the three professional practices, we designed a section for the instructional unit. Section Background $(\mathrm{CH} 1)$ is about the professional practice of a sports physiologist, Section Method (CH2) is about the monitoring of dike heights and Section Results and discussion (CH3) concerns the calibration of measuring instruments.

\section{Participating students}

To answer research question 1, we examined 415 $(198+190+12+15)$ students (see Table 1). In 2008, they were all five Voorbereidend wetenschappelijk onderwijs (VWO) students from two schools (A and B) and, in 2011, two groups which attended classes for the course NLT (schools A and C). The group $(n=15)$ of school A went through the instructional unit in the beginning of six VWO. One group (school C, $N=16$ ) was examined to answer RQ2. VWO stands for the Dutch secondary school type, grades 7 to 12 (five $\mathrm{VWO}=$ grade 11 , six $\mathrm{VWO}=$ grade 12 ), that gives entrance to selected university studies, the selection depending on the courses taken in the final three years of VWO. To measure the knowledge of the students, we have asked both groups, prior to administering the unit, whether they could write a formula in which a regression line and the related correlation were calculated. They unanimously answered no to both questions. This was expected as the topic correlation and regression was not a mandatory part of the VWO curriculum. On the other hand, the students had already learned about statistical measures such as mean and median in their mathematics programme, and they could calculate the standard deviation of a data set.

\section{Measurement instruments}

To answer research question 1 , we used questionnaires. Prior to the completion of the instructional unit, in a questionnaire $\left(\mathrm{S} \_1\right)$, we asked students $(n=198)$ their opinion about a possible teaching-learning strategy which would be based on professional practices. We asked questions about the aspects that we thought to be meaningful for students (see Table 2). We asked for examples of whether such a teaching-learning strategy would help the students to understand the usefulness of the course material (item 1); also whether it gave them motivation to learn (item 2), whether they expected that the techniques they learned would be applicable in other subjects (items 3 and 4) and whether they found it useful if the course material would go across multiple school disciplines (item $5)$. The students could express their views on a five-point scale from strongly disagree to strongly agree. In the next cycle, the questionnaire was improved (S_2) and shortly after administered to a new group of students in five VWO $(N=190)$. One improvement was that the first question was split into two questions: With a professional practice as a basis for the curriculum I see the usefulness of the curriculum, and it motivates me to learn these techniques was split into With a professional practice as a basis for the curriculum I see the usefulness of the curriculum. and If the techniques of the curriculum can be used by professionals, it motivates me to learn these techniques. Another example is that some words were changed. For example, real process was changed to is done the same way as in the lessons .

Table 1 Number of students surveyed in the analyses of 2008 and 2011

\begin{tabular}{|c|c|c|c|c|c|c|c|}
\hline \multirow{2}{*}{ School } & \multirow{2}{*}{ Year } & \multicolumn{4}{|l|}{ RQ1 } & \multicolumn{2}{|l|}{ RQ2 } \\
\hline & & S_1 & S_2 & S_3 & S_4 & Student work/posttest & Posttest \\
\hline $\mathrm{A}$ & 2008 (June) & 198 & & & & & \\
\hline$A$ and $B$ & 2008 (November) & & 190 & & & & \\
\hline$A$ & 2011 & & & $12\left(\begin{array}{ll}15 & 3\end{array}\right)$ & 12 (15 3) & & \\
\hline \multirow[t]{2}{*}{ C } & 2011 & & & $15(161)$ & $15(161)$ & $14(162)$ & 16 \\
\hline & Total & 198 & 190 & 27 & 27 & 14 & 16 \\
\hline
\end{tabular}

In brackets, the number of students in the group and the number of students whose information was not complete. 
Table 2 Percentage score of eight items from S_2 $(N=190), S \_3(N=27)$ and S_4 $(N=27)$

\begin{tabular}{|c|c|c|c|c|c|c|c|}
\hline Item & Aspect meaningfulness & Questionnaire & -- & - & 0 & + & ++ \\
\hline \multirow{3}{*}{$\begin{array}{l}\text { With a professional practice as a basis for the curriculum } \\
\text { I see the usefulness of the curriculum. }\end{array}$} & \multirow[t]{3}{*}{ Usefulness } & S_2 & 2 & 5 & 30 & 53 & 11 \\
\hline & & S_3 & 0 & 0 & 26 & 67 & 7 \\
\hline & & S_4 & 0 & 15 & 11 & 63 & 11 \\
\hline \multirow{3}{*}{$\begin{array}{l}\text { If the techniques of the curriculum can be used by } \\
\text { professionals, it motivates me to learn these techniques. }\end{array}$} & \multirow[t]{3}{*}{ Motivation } & S_2 & 2 & 8 & 24 & 51 & 15 \\
\hline & & S_3 & 4 & 4 & 37 & 48 & 7 \\
\hline & & S_4 & 4 & 7 & 33 & 52 & 4 \\
\hline \multirow{3}{*}{$\begin{array}{l}\text { I think I might be able to use the technique to determine } \\
\text { a regression line in more school subjects. }\end{array}$} & \multirow[t]{3}{*}{ Apply } & S_2 & 4 & 4 & 19 & 56 & 16 \\
\hline & & S_3 & 7 & 7 & 15 & 52 & 19 \\
\hline & & S_4 & 4 & 7 & 4 & 70 & 15 \\
\hline \multirow{3}{*}{$\begin{array}{l}\text { I think that the technique of correlation and regression is } \\
\text { needed within each of the natural sciences. }\end{array}$} & \multirow[t]{3}{*}{ Apply } & S_2 & 2 & 7 & 46 & 37 & 8 \\
\hline & & S_3 & 0 & 15 & 15 & 59 & 11 \\
\hline & & S_4 & 4 & 11 & 19 & 56 & 11 \\
\hline \multirow{3}{*}{$\begin{array}{l}\text { I find it interesting when I learn something about another subject, } \\
\text { such as biology or physics, when I follow a statistics unit. }\end{array}$} & \multirow[t]{3}{*}{ Connection } & S_2 & 14 & 24 & 29 & 27 & 6 \\
\hline & & S_3 & 4 & 22 & 26 & 37 & 11 \\
\hline & & S_4 & 7 & 11 & 37 & 37 & 7 \\
\hline \multirow{2}{*}{$\begin{array}{l}\text { I have gained more insight into how statistics can be used by } \\
\text { a sports physiologist/official of the Ministry of Water management }\end{array}$} & \multirow[t]{2}{*}{ Connection } & S_3 & 0 & 11 & 11 & 67 & 11 \\
\hline & & S_4 & 0 & 4 & 15 & 74 & 7 \\
\hline $\begin{array}{l}\text { I think determining a threshold point in the practice of a } \\
\text { physiologist is done the same way as in the lessons. }\end{array}$ & Authenticity & S_3 & 0 & 37 & 33 & 26 & 4 \\
\hline $\begin{array}{l}\text { I think that the determination of the date on which action } \\
\text { should be taken to raise a dike is in reality the same as in } \\
\text { the lessons. }\end{array}$ & Authenticity & S_4 & 15 & 19 & 37 & 26 & 4 \\
\hline
\end{tabular}

In this table, the abbreviations --, - , 0, + and ++ refer to strongly disagree to strongly agree, respectively.

We give the results of this second questionnaire as far as the items are relevant to the research questions in this article and indicate whether the students think an instructional unit based on professional practices to be meaningful.

To investigate whether students perception of meaningful is the same as the researchers, we also interviewed some students.

Furthermore, we have asked the final two groups of students ( $n=15$, six VWO, resp. $n=16$, five VWO) after the completion of $\mathrm{CH} 1\left(\mathrm{~S} \_3\right)$ and $\mathrm{CH} 2\left(\mathrm{~S} \_4\right)$ whether they thought they had acquired more insight in the use of statistics into the presented professional practices (item 6) and whether they expected the exercises in the instructional unit to be authentic (items 7 and 8). For organizational reasons, we could not ask the same questions about chapter 3 . Of the four students, some data are missing. These are reported in Table 1 , with a negative number. In the analysis, we therefore studied $12+15=27$ students.

Thus, it follows from the above that in order to answer research question 1 , we have examined four different sources: answers by students on (1) multiple choice questions, (2) open questions, (3) interviews with students and (4) excerpt examples of students work.
To answer research question 2 (about the connections between mathematics, statistics, science and professional practices), during the instructional unit, we asked students to fully elaborate on paper their answers for the assignments. We have collected and analysed all this written work, which we will refer to as the students work from now on. Next, in a posttest after the completion of the instructional unit, we analysed on the basis of the students work whether they had mastered the material and could explain the connections. The posttest involved all students. Within the framework of the bridge metaphor, we examine five possible connections between mathematics, statistics, science and professional practice (Figure 1). Table 3 shows which links relate to which tasks in the posttest.

In the analysis of the students work and the posttest, we investigated whether the instructional unit contributes to the links that students perceive between mathematics $(\mathrm{M})$, statistics $(\mathrm{S})$, professional practice $(\mathrm{P})$ and natural science $(\mathrm{N})$. We developed an analytical model (see Figure 1 and Tables 3 and 4) for analysing the written response. With this, we have distinguished the students work of the last group $(N=16)$ about elements $\mathrm{M}, \mathrm{S}, \mathrm{P}$ and $\mathrm{N}$ (Table 4) and the students answers coded with MS, MP, PS, PN and/or SN (Table 5). 
Table 3 Possible connections MS, MP, PS, PN, and SN to be made in the posttest

\begin{tabular}{llllll}
\hline Task & MS & MP & PS & PN & SN \\
\hline Task 1 & $\times$ & $x$ & $x$ & $x$ & $\times$ \\
Task 2 & $x$ & & & & \\
Task 3 & $x$ & & $x$ & & \\
Task 4 & $\times$ & & $x$ & $x$ & $\times$ \\
\hline
\end{tabular}

See Figure 1 for the meaning of the codes.

\section{Data analysis}

\section{Research question 1}

In the analysis of the questionnaires, we compared the same relative frequency of relevant items at $\mathrm{S} \_2, \mathrm{~S} \_3$, and S_4. S_2 also contained an open question, where the students were invited to explain why they do or do not appreciate professional practices as the basis of the curriculum. The answers were coded as positive, negative or inconclusive. The inter-rater reliability with regard to these three categories was measured using Cohens kappa (Cohen 1960) and proved to be very high (.91).

\section{Research question 2}

The first task of the unit was similar to the first task of the posttest for a comparison between relationships that students make at the beginning and end of the instructional unit. The work of two students was not complete and is not included in the analysis. Multiple codes per response on the task were possible, which was necessary

Table 4 Definitions of the considered elements

\begin{tabular}{ll}
\hline Element & Examples \\
\hline $\mathrm{M}$ & The student indicates that calculations must be carried \\
& or used \\
& The student performs a calculation \\
& The student gives a mathematical relationship between \\
& two quantities \\
& The student uses formulas \\
& The student interprets or refers to a graph or table using \\
& the data \\
& The student uses a statistical term (e.g., mean, variation, \\
& SD, residual, etc.) \\
& The student mentions a methodological aspect (e.g., \\
& representativeness, keeping certain conditions \\
& constant, etc.) \\
& The student mentions a sport physiological advice \\
The student refers to an authentic practice such as \\
measuring fitness or the determination of the threshold \\
point \\
The student mentions a quantity from natural science \\
(e.g., weight, age) \\
The student performs a connection between two \\
scientific properties (e.g., heart rate and intensity of \\
training)
\end{tabular}

Table 5 Codes used to code students work and task 1 from the posttest

\begin{tabular}{ll}
\hline Code & Explanation \\
\hline MS & $\begin{array}{l}\text { The student involves mathematical techniques in the } \\
\text { interpretation of the graphical representation of the data }\end{array}$ \\
MP & $\begin{array}{l}\text { The student involves mathematical techniques in } \\
\text { formulating a sport physiological advice }\end{array}$ \\
PS & $\begin{array}{l}\text { The student uses statistical techniques to formulate a } \\
\text { sport physiological advice }\end{array}$ \\
PN & $\begin{array}{l}\text { The student works with a physical/biological variable } \\
\text { in the sports physiological advice }\end{array}$ \\
SN & The student explains statistical results from the \\
& underlying physical/biological aspects
\end{tabular}

given the research question, but which did affect the inter-rater reliability (Cohen s kappa), which was measured on the basis of 150 student responses. The measured value of kappa (.61) is still considered substantial by Cohen (1960). We also give some examples of connections found in class discussions.

\section{Results and discussion}

RQ1: to what extent is education based on a professional practice meaningful for students?

The first item of the questionnaire was with a professional practice as a basis for the curriculum I see the usefulness of the curriculum of S_2 $(N=190)$. The response shows that prior to the unit most students $(+$ and $++: 53+11=$ $64 \%$ ) expected to see the usefulness (Table 2). One hundred twenty-three respondents out of 190 gave an optional explanation. Of the explanations, 103 were positive, 12 negative and 8 unclear. Examples of positive explanations are the following:

- Because I often can t see the usefulness of certain subjects . [usefulness]

- You see at least its usefulness in it . [usefulness/motivation]

- It [the professional practice] gives better understanding of your ultimate goal . [motivation]

- You can use it [concepts learned via the unit] daily, and also in other subjects . [application/connection]

- It sood to show you where to apply your knowledge. Later when you have finished school. And you become more motivated to study . [apply/motivation]

- I think its good to use professional practices in the curriculum, because then you know how it is used/ applied in reality. [application/authenticity]

- Handy [to base the unit on APPs] for example for other subjects . [connection].

One negatively coded response was No, I think it is not effective. Another student explicitly made it clear that 
coherence was important to her: I would like to see professional practices as the basis for the curriculum, because now I can easily make connections between different subjects .

We concluded that the results of S_2 indicate that most students, prior to the unit, see the point of using professional practices. Because this also was an outcome of S_1, we had sufficient reasons to develop the instructional unit.

From S_3, it appeared that students who went through the instructional unit also considered the teaching learning strategy as useful after the completion of $\mathrm{CH} 1$ of the instructional unit. These students $(67 \%+7 \%=74 \%)$ were even more positive (+ and ++ added). Even after $\mathrm{CH} 2$, which included the mathematical foundation of correlation and regression, the majority (74\%) of the students still gave positive response (S_4). A binomial sign test to assess responses per student to $S_{-} \_3$ and $S \_4$ yielded $p=0.60$. This indicates that the opinions of students did not change statistically significantly, not even after the mathematical-theoretical approach of $\mathrm{CH} 2$.

The answers to items 1 to 8 show a positive inclination. Only the item about the authenticity of the lesson activities related to professional practice (items 7 and 8) is scored in a wider range. This finding is consistent with our observation that the students were aware of the fact that the professional practices are educationalized. For example, one student mentioned that in reality more factors are important. He mentioned, for example, that nowadays for skaters the material of their sportswear is very important. Sports physiologists do not limit themselves to heart rate, the focus in the instructional unit, but also involve other variables in preparing an advice.

The researcher (R) also interviewed some students and asked their opinions of the educational strategy:

Student 1: You learn [in this unit] a lot of things. Often I say, you cannot use the learned concepts much. Now [in this unit] you do! [usefulness]. Student 2: I liked that you deal with people who are getting involved in statistical work to see what they do statistically. [motivation] Especially, at the moment when you learn a technique you can apply later. [application]. R: Do you have any idea where you could apply it? Student 2: I have not checked all professions, but in a lot of professions you have to find a dependency. [authenticity].

Student 3: You find this [concepts of the unit] in reality. [authenticity].

Student 4: Yes, more than you think. You will not realize it, but in all pilots, physicists, chemists, mathematicians things, you have to deal with dependency. [connection].
Student remarks such as these helped us to interpret the answers in the questionnaires and helped us to conclude that students had the same interpretation of meaningfulness as we did.

\section{Research question 2: relations between the natural sciences and professional practices Comparison of the connections made by students}

In this section, we discuss the extent to which students have learned to make connections. The first task of the instructional unit and of the posttest was:

Sports physiologists often determine the threshold point of the heartbeat of their clients.

a. What do we mean by threshold in this case?

b. Why is it important to measure this threshold point?

Comparison of the responses to this task shows that after the completion of the instructional unit, the students often more clearly saw a link between science disciplines and professional practice than at the start of the unit (Table 6). Only the relationship between mathematics and the professional practice shows just a negligible increase. At the beginning, the relationship between mathematics and statistics is not detected, and after working through the unit, it clearly was. In this task, we assumed that the students would develop a mathematical model for the measurements (MS). Seven students did so. Three of them made a drawing similar to Jan s in Figure 2.

Another student, Sherin, wrote The point where the line between heart rate and power deviates from the line from the first point is where you get acidification and helps to find the heartbeats zones with different intensity. We interpreted this as Sherin explaining the statistical result from the underlying biological aspect of the threshold between aerobic and anaerobic metabolism (SN). After this remark, he made a drawing like the one in Figure 2 but with heart rate zones. We coded this with MS because

Table 6 Number of students who acknowledged the links MS, MP, PS, PN and SN

\begin{tabular}{lll}
\hline Link & Introductory task & Posttest \\
\hline Mathematics and statistics (MS) & 0 & 7 \\
$\begin{array}{l}\text { Mathematics and professional } \\
\text { practice (MP) }\end{array}$ & 2 & 3 \\
$\begin{array}{l}\text { Professional practice and statistics (PS) } \\
\text { Professional practice and natural }\end{array}$ & 5 & 13 \\
science (PN) & 4 & 13 \\
Statistics and natural science (SN) & 1 & 12 \\
\hline
\end{tabular}

Number of students who acknowledged the links MS, MP, PS, PN and SN for the preliminary task of the instructional unit and during the posttest $(N=16)$. 


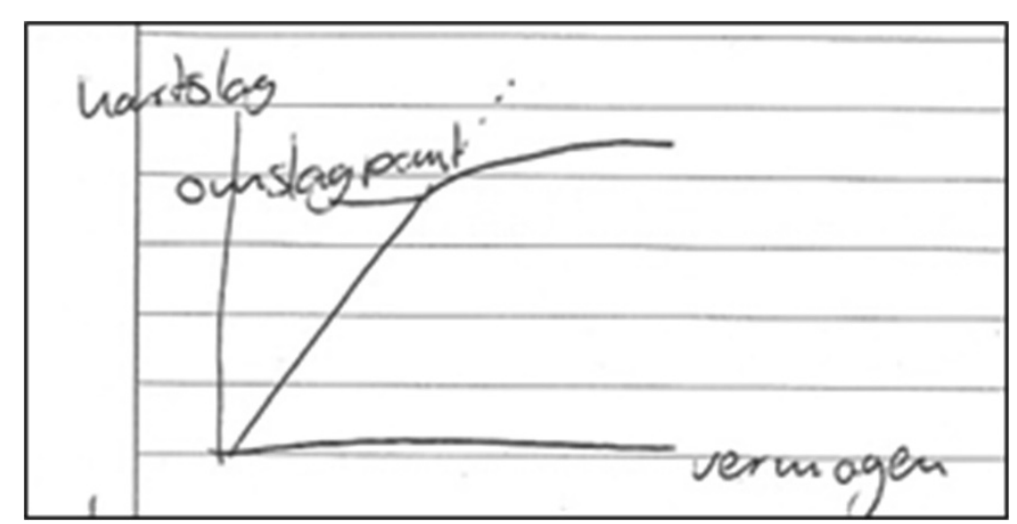

Figure 2 Students model for the determination of the threshold point. Jan s illustration of the model for the determination of the threshold point between aerobic and anaerobic metabolism.

we thought Sherin needed mathematical techniques such as graphing to interpret the data. He continued Then you can draw the different heart rate zones and then you can see in which areas you need to train and then you know where you find your threshold between aerobic and anaerobic metabolism. With this phrase, he uses statistical techniques to formulate a sport physiological advice (PS).

Three students explicitly linked the model shown in Figure 2 with the advice that a sports physiologist can give to clients (MP). For example, You can calculate the threshold point and advise the client to train just under this point. This student meant to train in such a way that your heartbeat is a little lower than the threshold point and connected the calculation to advice for a client (MP). Most students (13) associated statistical techniques (e.g., regression line for the linear portion) with the physiological advice (PS). These thirteen included the scientific terms aerobic and anaerobic metabolism with their advice $(\mathrm{PN})$. They wrote that if training takes place in the anaerobic section too often (above the threshold, omslagpunt in Figure 2), the threshold point goes down, in which case acidification starts earlier. So an athlete should train slightly below the threshold point. Twelve students linked their physiological advice with the data obtained during the testing of clients (SN).

The extent to which students made connections in the posttest In Table 7 the posttest results are the average student scores per order. The students were sufficiently able to apply concepts from the instructional unit: the average score was $64 \%$.

Task 2 involved the relationship between mathematics and statistics. The task assessed what students had learned in $\mathrm{CH} 2$ about the mathematical background of correlation and regression. In this task, we asked the students to describe the sequence of steps by which the least squares method determines the coefficients of the regression line. Eight students did this perfectly, four made a small mistake, and no one had a completely wrong answer. Also, we asked them to explain the least squares method. This was the most difficult part of task 2 (mean score 53\%). Furthermore, in task 2, we gave the students steps from the method of finding a normal equation in a random order. The students had learned to draw a scatter plot of points $\left(d_{\mathrm{i}}, H_{\mathrm{i}}\right)$ with $d$ for day and $H$ for deviation and represent a regression line by: $\hat{H}=a \cdot d+b$, with $a$ and $b$ as regression coefficients. Also, they had learned to calculate the distance from a point to the regression line (residual) with $a \cdot d_{i}+b \quad H_{i}$. Using the least squares method, the students were able to find the best fit for the regression line by minimizing the sum of residual squares. They had to connect mathematics and statistics:

$$
S \quad \sum_{1}^{n} a \cdot d_{i} \quad b \quad H_{i}^{2}
$$

Derivations to $a$ and $b$ gave them a system of two normal equations:

$$
\left\{\begin{array}{lll}
a \sum d_{i}^{2} & b \sum d_{i} & \sum d_{i} H_{i} \\
a \sum d_{i} & n \cdot b & \sum H_{i}
\end{array}\right.
$$

The students had learned to calculate all the sigmas and were able to solve the system.

In task 2, we asked them to write the steps for finding a normal equation in the correct order and to explain each step. Most students were able to write the steps in the proper order, but their explanations sometimes were rather weak (see Figure 3).

In task 3 , the students were given 44 measurements of dike deformations. To test whether students could explain the MS-relation, they had to calculate the time where raising the dike could no longer be avoided. Apart 
Table 7 Connections MS, MP, PS, PN and SN made in the tasks of the posttest and scores of the final group ( $N=16)$

\begin{tabular}{|c|c|c|c|c|c|c|c|c|}
\hline Task & MS & MP & PS & PN & SN & Max. score & Mean score (SD) & Score (\%) \\
\hline Task 1 & $x$ & $x$ & $x$ & $x$ & $x$ & 2 & $1.1(0.6)$ & 55 \\
\hline Task 2 & $x$ & & & & & 9 & $6.3(1.8)$ & 69 \\
\hline Task 3 & $x$ & & $x$ & & & 16 & $11.0(3.3)$ & 69 \\
\hline Task 4 & $x$ & & $x$ & $x$ & $x$ & 11 & $6.1(2.3)$ & 55 \\
\hline
\end{tabular}

from some sloppiness, all students could calculate the correlation. Except for one student, all students could determine the formula for the regression line.

In task 3, the relation with the professional practice was very important (PS), because when only the regression line is used to calculate when the embankment is to be incremented, it will be too late: there are also points below the regression line. The assignment specified that students should take a safety margin. Five did not. One student used Excel for this margin (see Figure 4).

The other students adapted a well-known formula. By applying statistical know-how to a mathematical model (regression line), the students showed that they also saw the connection between mathematics and statistics (MS). The fourth task coincided with the chapter on the calibration of measuring instruments. The students were given a new context in which, for nine samples of blood serum, the concentration of iron and the corresponding absorption were given. Except for one student, all could determine the calibration line (regression line). To emphasize the relation with the natural sciences as taught at school, points were deducted if incorrect letters for the variables were used. Also, the students were asked to determine the iron concentration of a patient for whom the measured absorbance of a blood sample was given. Thirteen students did this correctly. The other three had problems in connecting the scientific terms to the statistical concept of regression line ( $\mathrm{SN}$ and $\mathrm{PN}$ ).

In task 4, students also faced a context that was new for them: atomic absorption spectrometry. The students were given the data (the amount of added silver and the absorption) of nine blood samples. Most students (15) were able to determine the regression line, but only two students were able to perform the steps necessary to calculate the concentration of the original sample. In this task, the students were required to combine at the same time mathematical, statistical and natural sciences with professional techniques (MS, PS, PN and $\mathrm{SN})$.

We give some examples from class discussions on how students made the connections:

\section{Mathematics and statistics (MS)}

With the following fragment $(\mathrm{CH} 1)$, we show an example in which a student, Paul (all names are pseudonyms), indicates a link between mathematics and statistics. Paul explains how he drew the regression line intuitively: by the centre of the point cloud. When asked by the teacher $(\mathrm{T})$ what he means by centre, Paul indicates that he looks vertically where the points are.

Paul: Take the mean of all the points above each other [with the same value on the horizontal axis].

T: Say, the means of the $y$ values.

Paul: Yes.

T: Than you get a line with above and beneath ..? Paul: The same.

T: What do you mean with the same?

Paul: Approximately the same amount. How shall I explain that?

T: The same amount is good for me, but finish your sentence.

Paul: Not the same amount of points, but, say, the distance. If you add up all the distances between all the points and the line together, you get the same above and below.

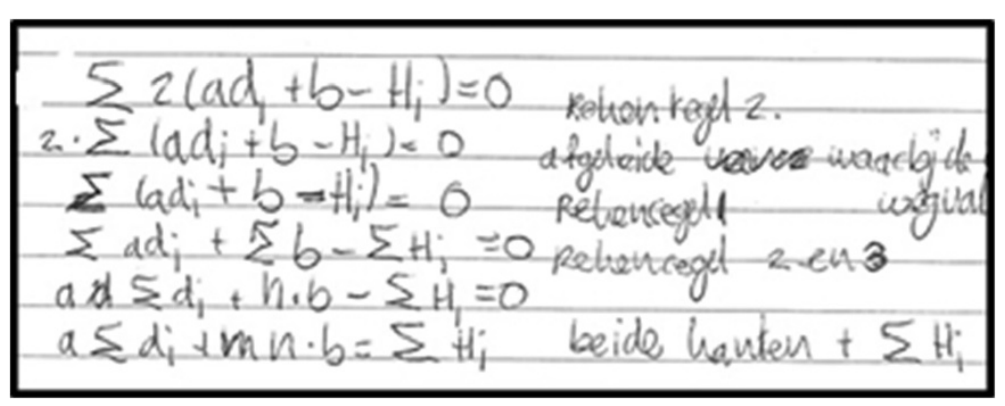

Figure 3 Part of a student s response on task 2 of the posttest. 


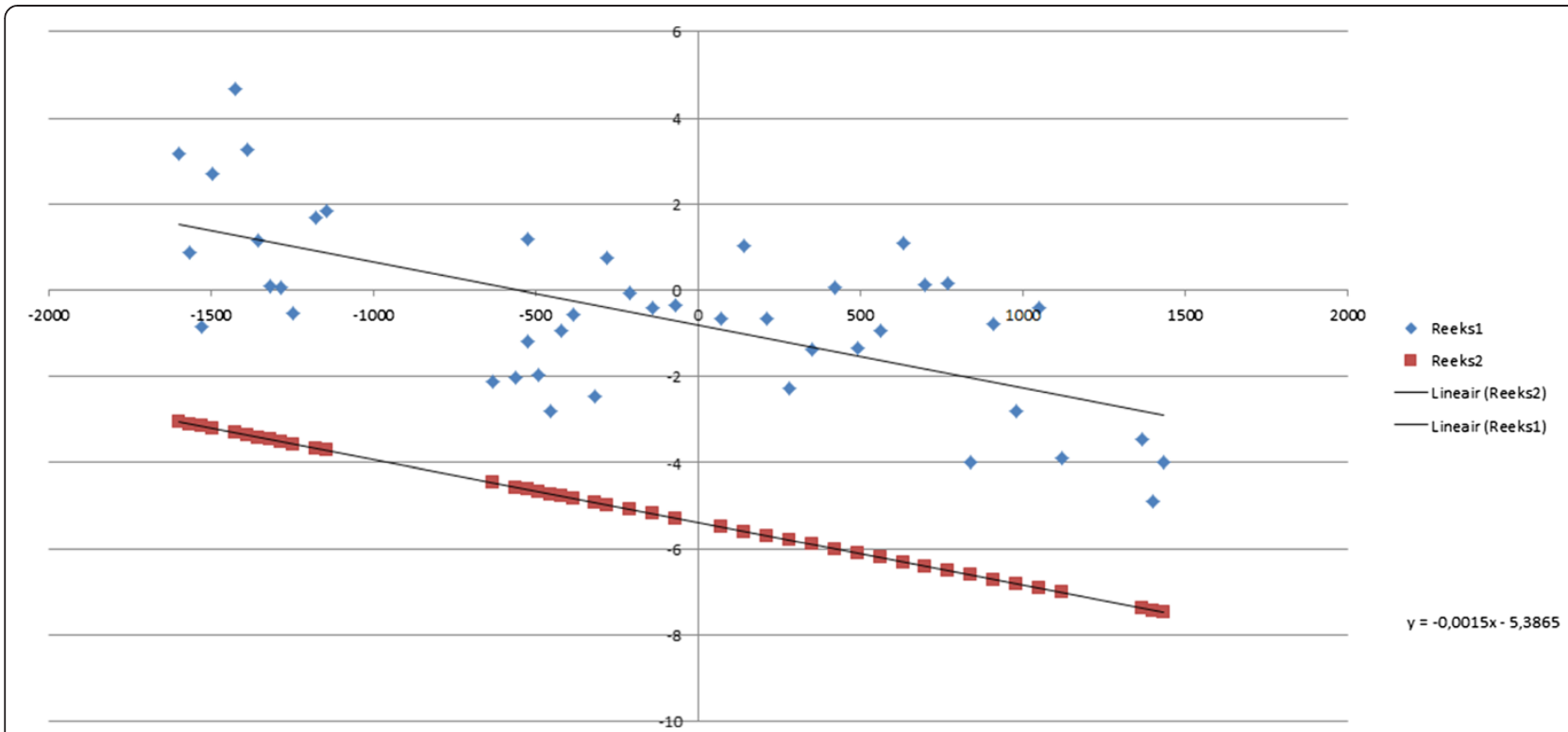

Figure 4 Excel output from one of the students. The upper line is the regression line. The lower line is constructed by subtracting three times the SD of the residuals from the regression values (according to a discussion about the rules of thumb for a normal distribution).

At this stage, the students have not yet learned the formal background, for instance, the least squares method. They had intuitively searched for a method to draw the regression line. In fact, Paul describes here that he looks at the sum of residues. He connects mathematical techniques, such as the sum of all distances (residues) calculated, with statistical techniques, such as determining a regression line.

\section{Mathematics and professional practice (MP)}

In the discussions on dike heights $(\mathrm{CH} 2)$, students regularly make connections. On a question from the teacher on how you can determine when to raise a dike, student Jan makes a clear link between mathematics and the professional practice. On the basis of the regression line, he shows that you can extrapolate to come to an advice about when a dike should be raised.

Jan: Once we learned in mathematics that you can continue to calculate.

T: Extrapolate?

Jan: Yes, extrapolate.

T: Can you explain what you mean by that?

Jan: I did not do it for a long time. But, when you have a certain amount of points and continue to calculate with the found slope, than you can predict when to take action to heighten the dike.

In this fragment, Jan explicitly linked what he had learned in mathematics to the professional practice.
Professional practice and statistics (PS)

In the last fragment, Jan involves the professional context in his remarks. He also makes a connection between the professional practice and statistics:

Jan: If you only look at the regression line of the dike heights to make your prediction of the day to raise the dike, you may have a problem with outliers. Suppose that the [regression] line at day 45 gives a value and another point is suddenly very deep, then you have a problem.

Then, this was followed a discussion about an appropriate safety margin around the regression line and how to use such a safety margin in the advice to indicate when a dike should be raised arises.

\section{Professional practice and natural science (PN)}

Students making a connection between the professional practice and science were obvious in $\mathrm{CH} 1$, because determining the threshold point between aerobic and anaerobic metabolism was an outcome there. Three students with biology as part of their school subjects, voluntarily gave a presentation of $10 \mathrm{~min}$ on the difference between aerobic and anaerobic metabolism. In the chapter on the dike heights, the scientific aspect was somewhat less of an issue, but students did involve scientific aspects such as landslides and erosion in their opinion on the moment of heightening dikes.

Jan: I live on reclaimed land, thus when the water rises we have to raise everything [dikes and ground] and continue to pump. 
T: Why does that ground sink?

Rolf: It s something with baseplates.

T: Yes, shifts of baseplates.

Jan: The one plate slides under the other or something.

$\mathrm{T}$ : But imagine simple things you can see with your naked eye.

Jan: Groundwater.

$\mathrm{T}$ : Yes, and erosion.

Rolf: Oh yes!

D: Why erosion?

Rolf: Then there is the top slightly.

Rolf: The surface wears.

Then, this was followed a discussion about erosion and landslides. When another student asked John whether landslides occur in the Netherlands, and the teacher referred to the internet, these students found to their surprise that earthquakes do occur in the Netherlands.

\section{Statistics and natural sciences ( $S N)$}

To show that students connect statistics and natural sciences, we give an example from the final chapter on the calibration of measuring instruments. The students have received data from two thermometers and the teacher asks which is more precise.

Gijs: The standard deviation is smaller, and the correlation is higher.

$\mathrm{T}$ : Why did it not indicate the same value every time?

Diede: Measurement error.

Sherin: If the [verification] pool is not 20 degrees.

$\mathrm{T}$ : The pool is exactly 20 degrees.

Sherin: If a little mercury above in thermometer .....

$\mathrm{T}$ : But a sensor thermometer might not contain mercury.

Sherin: Thats true. If the resistance is just a little different.

T: But how could that resistance be different?

Sherin: If it is warmer.

$\mathrm{T}$ : But it s not warmer.

Patrick: Because of the pressure.

Marije: Yes, by air pressure.

The discussion about the differences continued to search for explanations and eventually ended with a discussion of the effect of molecules. With statistics as a starting point, the teacher brought the students to scientific speculations about molecules.

\section{Conclusions}

In answer to the first research question, we conclude that many students experience an instructional unit based on professional practices as meaningful.
In this study, we focussed on usefulness, motivation, apply, connection, and authenticity as aspects of meaningfulness. Both questionnaires, one prior to the experiments and the other after the completion of the unit, indicate that students widely appreciated such an educational strategy. They indicated that they see the need for a curriculum that is based on professional practices, that such an instructional strategy motivates them, and that they think they will be able to apply what they have learned in other disciplines as well. The opinions of the students were more divided about the authenticity of the teaching material, which is understandable since the professional practices had been educationalized before being introduced, especially by taking away some of the complexity. Despite the fact that in the questionnaires the five aspects of meaningfulness were balanced present (authenticity less than the others), we observed that especially motivation and apply dominated over the others in the students spoken interactions. We did not quantify this, but we have many recordings with students remarks about the fact that the approach based on authentic practices is motivational and that they were able to apply the learned concepts.

Our conclusion that students find it meaningful that an instructional unit is based on professional practices (RQ1) is supported by data from multiple choice questions, open questions, interviews with students and excerpt examples of students work.

In the study presented here, we argued that coherence is not enough to understand relationships. When making connections, it is also important that students master the concepts and are able to apply them. In answer to our second research question, we conclude that the students clearly made more connections between mathematics, statistics, natural science and professional practice after the completion of the unit than at the start of the module. The relationship between mathematics and the professional practice is not recognized in the students answers as strongly as the other connections. This is understandable because in this instructional unit the connection between mathematics and the professional practice (MP) was in accordance with the design, which presents the connection primarily via statistics. So, in this design, statistics acted like a bridge between mathematics and a natural science, and no direct connection between mathematics and the professional practice was designed. We assume that our analysis model can be adapted for connections between other school subjects and professional practices. For example, we suggest that a professional practice could be used to inspire educational materials to bridge a foreign and a natural language. Also, we conclude that our instructional unit helped the students to apply the new concepts in other disciplines. The analysis of the posttest with tasks in which various connections 
were involved shows that students were able to apply the learned concepts. They were also able to make the required connections.

With regard to our answer to the second research question, we note that the measured inter-rater reliability is acceptable, although still quite low (0.61). We attribute this to the fact that for each item multiple codes were possible. Furthermore, the boundaries between the five areas are not always clear (2.3). In addition, the second coder/researcher had only the transcripts and had not been involved in acquiring the data.

In answer to the main question, we conclude that we designed an example of an instructional unit based on professional practices which was meaningful for most of the students, also after the completion of the unit. We observed a relevant increase in the number of times that students made connections between mathematics, statistics, natural science and some professional practices. Although the literature, e.g., Berlin and White 2012, indicates that it is difficult to make the relationship between science and contexts clear to the students, the design on the basis of professional practices, with a focus on meaning from a student s perspective, seems a promising direction to take. After all, the use of professional practices helped the students to make connections in a natural way. Further research is needed to investigate whether and when professional practices can help to improve curricular coherence in other situations. This also asks for comparative research. Further research is also needed in order to implement education based on authentic professional practices and to better understand the role of the teacher.

\section{Additional file}

Additional file 1: Table of contents of the instructional unit statistics

as bridge between mathematics and science.

\section{Abbreviations}

NLT: nature, life and technology; cTWO: Commissie Toekomst Wiskunde Onderwijs; NiNa: Commissie Vernieuwing Natuurkundeonderwijs havo/vwo; CVBO: Commissie vernieuwing Biologieonderwijs; M: mathematics; S: statistics; P: professional practice; N: natural science; MS: connection between mathematics and statistics; MP: connection between mathematics and the professional practice; PS: connection between the professional practice and statistics; PN: connection between the professional practice and the natural sciences; $\mathrm{SN}$ : connection between statistics and the natural sciences; WW: voorbereidend wetenschappelijk onderwijs (pre-university track).

\section{Competing interests}

The authors declare that they have no competing interests.

\section{Authors contributions}

$A D$ carried out the design of the research, educational materials, data collection, the analyses, and drafted the manuscript. $A B$ contributed to the data collection, participated in the design of the study and offered editorial support to the document. JvM contributed to the design of the study, editorial support, advice and general supervision. HE contributed to the design of the education materials, editorial support of the document, advice and general supervision. All authors read and approved the final manuscript.

\section{Acknowledgements}

The research was funded through grant DUDOC UU3 by the Platform B?ta Techniek. This article is based on a Dutch article published in Pedagogische Studien (Dierdorp et al. 2013). We thank all reviewers for their helpful comments on the earlier versions of this manuscript.

Received: 9 May 2014 Accepted: 17 October 2014

Published online: 15 November 2014

\section{References}

AAAS. (1989). Project 2061: Science for All Americans. Washington, DC: American Association for the Advancement of Science.

Anderson, JE, \& Sungur, EA. (1999). Community service statistics projects. The American Statistician, 53(2), 132136.

Apotheker, J, Bulte, A, de Kleijn, E, Van Koten, G, Meinema, H, \& Seller, F. (2010). Scheikunde in de dynamiek van de toekomst over de ontwikkeling van scheikunde in de school van de 21 eeuw. Enschede: SLO.

Barab, SA, \& Squire, KD. (2004). Design-based research: putting a stake in the ground. Journal of the Learning Sciences, 13, 114.

Bennett, J, Lubben, F, \& Hogarth, S. (2007). Bringing science to life: a synthesis of the research evidence on the effects of context-based and STS approaches to science teaching. Science Education, 91, 347370.

Ben-Zvi, D, \& Garfield, J. (2008). Introducing the emerging discipline of statistics education. School Science and Mathematics, 108, 355361.

Berlin, DF, \& Lee, H. (2005). Integrating science and mathematics education: historical analysis. School Science and Mathematics, 1, 1524.

Berlin, DF, \& White, AL. (1992). Report from the NSF/SSMA Wingspread Conference: a network for integrated science and mathematics teaching and learning. School Science and Mathematics, 92, 340342.

Berlin, DF, \& White, AL. (2012). A longitudinal look at attitudes and perceptions related to the integration of mathematics, science, and technology education. School Science and Mathematics, 1, 2030.

Boaler, J. (1993). Encouraging the transfer of school mathematics to the real world through the integration of process and content, context and culture. Educational Studies in Mathematics, 25, 341373.

Boersma, KTH, Van Graft, M, Harteveld, A, De Hullu, E, De Knecht-van Eekelen, A, \& Mazereeuw, M. (2007). Leerlijn biologie van 4 tot 18 jaar. Uitwerking van de concept-context benadering tot doelstellingen voor het biologieonderwijs. Utrecht, the Netherlands: NIBI.

Boersma, K, Bulte, A, Kr?ger, J, Pieters, M, \& Seller, F. (2010). Samenhang in het natuumetenschappelijk onderwijs voor havo en wwo. Utrecht, the Netherlands: Stichting Innovatie van Onderwijs in B?tawetenschappen en Technologie (IOBT).

Bransford, JD, Brown, AL, \& Cocking, RR (Eds.). (2000). How People Learn: Brain, Mind, Experience, and School. Washington, DC: National Academy Press.

Clarke, D. (1988). The Mathematics Curriculum and Teaching Program Professional Development Package: Assessment Alternatives in Mathematics. Carlton, Vic.: Curriculum Corporation.

Claxton, G. (1991). Educating the Enquiring Mind: The Challenge for School Science. New York: Harvester Wheatsheaf.

Cohen, J. (1960). A coefficient of agreement for nominal scales. Educational and Psychological Measurement, 20(1), 3746.

cTWO. (2007). Rijk aan betekenis. Visie op vernieuwd wiskundeonderwijs. Utrecht, the Netherlands: Commissie Toekomst Wiskunde Onderwijs.

Davison, DM, Miller, KW, \& Metheny, DL. (1995). What does integration of science and mathematics really mean? School Science and Mathematics, 95(5), 226230.

Dierdorp, A, Bakker, A, Eijkelhof, HMC, \& van Maanen, JA. (2011). Authentic practices as contexts for learning to draw inferences beyond correlated data. Mathematical Thinking and Learning, 13, 132 151. http://dx.doi.org/10.1080/ 10986065.2011 .538294$.

Dierdorp, A, Bakker, A, Eijkelhof, HMC, \& van Maanen, JA. (2013). Betekenisvolle statistiek in beroepspraktijken als brug tussen wiskunde en natuurwetenschappen: evaluatie van een ontwerponderzoek. Pedagogische Studin, $90,418$.

Eccles, JS, Midgley, C, Wigfield, A, Miller Buchanan, C, Reuman, D, Flanagan, C, \& Iver, DM. (1993). Development during adolescence. The impact of stage-environment fit on young adolescents experiences in schools and in families. American Psychologist, 48(2), 90101. 
Erickson, T. (2002). Technology, Statistics, and Subtleties of Measurement: Bridging the Gap between Science and Mathematics. Cape Town: South Africa: Paper presented at the 6 th International Conference on Teaching Statistics (ICOTS-6).

Frykholm, J, \& Glasson, G. (2005). Connecting science and mathematics instruction: pedagogical context knowledge for teachers. School Science and Mathematics, 105(3), 127141.

Furner, JM, \& Kumar, DD. (2007). The mathematics and science integration argument: a stand for teacher education. Eurasia Journal of Mathematics, Science \& Technology Education, 3(3), 185189.

Galbraith, P, \& Stillmann, G. (2006). A framework for identifying student blockages during transitions in the modeling. Zentralblatt fr Didaktik der Mathematik, 38,143162

Gattuso, L. (2006). Statistics and mathematics. Is it possible to create fruitful links? In A Rossman \& B Chance (Eds.), Proceedings of the Seventh International Conference on Teaching Statistics. Salvador: Brazil.

Gellish, RL, Goslin, BR, Olson, RE, McDonald, A, Russi, GD, \& Moudgil, GV. (2007). Longitudinal modeling of the relationship between age and maximal heart rate. The American College of Sports Medicine, 39(5), 822829

Geraedts, CL, Boersma, KT, \& Eijkelhof, HMC. (2006). Towards coherent science and technology education. Journal of Curriculum Studies, 38(3), 307325.

Geraedts, CL, Boersma, KT, Huijs, HAM, \& Eijkelhof, HMC. (2001). Ruimte voor Sonate. Delft, the Netherlands: Stichting Axis.

Hurley, M. (2001). Reviewing integrated science and mathematics: the search for evidence and definitions from new perspectives. School Science and Mathematics, 101, 259268.

Lee, HS, \& Songer, NB. (2003). Making authentic science accessible to students. International Journal of Science Education, 25, 923948.

Lederman, NG, \& Niess, ML. (1997). Integrated, interdisciplinary, or thematic instruction? Is this a question or is it questionable semantics? Schoo/ Science and Mathematics, 97(2), 5758.

Mooldijk, A, \& Sonneveld, W. (2010). Coherent education in mathematics and physics: the theme of proportionality in mathematics and physics. In N Valadines (Ed.), Trend in Science and Mathematics Education (TiSME) (pp. 43 50). Cyprus: Cassoulides.

Moore, DS, \& Cobb, GW. (2000). Statistics and mathematics: tension and cooperation. The American Mathematical Monthly, 107, 615630.

NCTM. (2000). Principles and Standards for School Mathematics. Reston, VA National Council of Teachers of Mathematics.

NRC, National Research Council. (1996). National Science Education Standards. Washington, DC: National Academy Press.

Newmann, FM, Smith, B, Allensworth, E, \& Bryk, AS. (2001). Instructional program coherence: what it is and why it should guide school improvement policy. Educational Evaluation and Policy Analysis, 23, 297321.

Nieveen, N, Handelzalts, A, \& Van Eekelen, I. (2011). Naar curriculaire samenhang in de onderbouw van het voortgezet onderwijs. Pedagogische Studin, 88,249265

$\mathrm{NiNa}$, Commissie Vernieuwing Natuurkundeonderwijs havo/vwo. (2010). Nieuwe natuurkunde, advies-examenprogrammas voor havo en vwo. Amsterdam: Nederlandse Natuurkundige Vereniging.

NLT Steering Committee. (2007). Contouren van een nieuw btavak. Visie op een interdisciplinair vak: Natuur, Leven en Technologie. Enschede: SLO.

Prins, GT. (2010). Teaching and Learning of Modeling in Chemistry Education. Utrecht, the Netherlands: CD-B?ta Press.

Prins, G, Bulte, AM, Pilot, A, \& Van Driel, J. (2008). Selection of authentic modelling practices as contexts for chemistry education. International Journal of Science Education, 30, 18671890.

Rossman, A, Chance, B, \& Medina, E. (2006). Some key comparisons between statistics and mathematics, and why teachers should care. In GF Burrill (Ed.), Thinking and Reasoning with Data and Chance: Sixty-Eighth Annual Year Book of the National Council of Teachers of Mathematics (pp. 323 333). Reston, VA: NCTM.

Rudduck, JHS, \& Wallace, G. (1994). Coherence and students experiences of learning in secondary schools. Cambridge Journal of Education, 24, 197211.

Scott, P, Mortimer, E, \& Ametller, J. (2011). Pedagogical link-making: a fundamental aspect of teaching and learning scientific conceptual knowledge. Studies in Science Education, 47, 336.

Stuurgroep-NLT. (2007). Contouren van een nieuw btavak . Enschede: Stuurgroep-NLT.

Sunal, D, \& Furner, JM. (1995). Teaching Mathematics and Science not Mathematics or Science. Huntsville, Alabama: Paper presented at the NASA Teacher Enrichment Program Mid-Year Workshop at the Marshall Space Flight Center.
Van den Akker, JJH. (2009). Curriculum design research. In T Plomp \& N Nieveen (Eds.), An Introduction to Educational Design Research (pp. 37 51). Enschede: SLO.

Van den Akker, JJH, Gravemeijer, KPE, McKenney, S, \& Nieveen, N. (2006). Educational Design Research. London: Routledge, Taylor \& Francis.

Van de Giessen, C, Hengeveld, T, Van der Kooij, H, Rijke, K, \& Sonneveld, W. (2007). Eindverslag van werkgroep afstemming wiskunde-natuurkunde. Utrecht: cTWO and NiNa.

Van Oers, B. (1987). Activiteit en begrip. Proeve van handelings-psychologische didactiek. Amsterdam, the Netherlands: VU Uitgeverij.

Volman, M. (2011). Kennis van betekenis. Betrokkenheid als kwaliteit van leerprocessen en leerresultaten. Oratie Universiteit van Amsterdam.

Westbroek, HB. (2005). Characteristics of Meaningful Chemistry Education - The Case of Water Quality. Utrecht, the Netherlands: CD-B?ta Press.

Westra, R. (2008). Learning and Teaching Ecosystem Behaviour in Secondary Education. Systems Thinking and Modelling in Authentic Practices. Utrecht, the Netherlands: CD-B?ta Press.

Wild, CJ, \& Pfannkuch, M. (1999). Statistical thinking in empirical enquiry. International Statistical Review, 67, 223265.

Whitelegg, E, \& Parry, M. (1999). Real-life contexts for learning physics: meanings, issues and practice. Physics Education, 34(2).

\section{doi:10.1186/s40594-014-0009-1}

Cite this article as: Dierdorp et al.: Meaningful statistics in professional practices as a bridge between mathematics and science: an evaluation of a design research project. International Journal of STEM Education 2014 1:9.

\section{Submit your manuscript to a SpringerOpen ${ }^{\circ}$ journal and bene冈t from:}

- Convenient online submission

- Rigorous peer review

- Immediate publication on acceptance

- Open access: articles freely available online

- High visibility within the \eld

- Retaining the copyright to your article

Submit your next manuscript at $>$ springeropen.com 